\title{
I nfluence of diet supplementation with Saccharomyces cerevisiae on intake and nutrient utilization in Graded Murrah buffaloes
}

\author{
D. Srinivas Kumar*, J.Rama Prasad and E.Raghava Rao \\ Department of Animal Nutrition, \\ NTR College of Veterinary Science, Gannavaram-521 102. India. \\ * Corresponding author
}

\begin{abstract}
A feeding trial was conducted in graded Murrah buffaloes to study the influence of yeast culture (Saccharomyces cerevisiae CNCM I-1077 strain) supplementation on intake and nutrient utilization. 12 graded Murrah buffaloes with an average body weight of $465.4 \pm 20.92 \mathrm{~kg}$ were randomly divided into two groups (Control and treatment) of 6 animals each. Animals in both the groups received a basal diet comprising of roughages and concentrates separately to meet the maintenance and production requirements (ICAR, 1998). In addition, the animals in treatment group received yeast culture @ $0.5 \mathrm{~g} / \mathrm{animal} /$ day. The average DMI of buffaloes during the digestion trial was 114.31 and $119.24 \mathrm{~g} / \mathrm{kg}$ W0.75 respectively, in control and treatment groups. The digestibility coefficients of gross nutrients and fibre fractions showed non-significant differences between the control and treatment groups, though the values were found to be comparatively higher in the yeast supplemented group. The DCP and TDN contents were observed to be 8.03 and 53.06 per cent in control group and 8.15 and 54.06 per cent in treatment groups, respectively. It can be concluded that yeast culture did not show any significant positive effect on nutrient utilization in graded Murrah buffaloes.

Key words: Yeast culture, DMI, Nutrient utilization.
\end{abstract}

\section{I ntroduction}

Yeast cultures have been fed to dairy cattle for more than 60 years with varied response. In some studies, yeast cultures improved dry matter intake (Williams et al., 1991; Wohlt et al., 1991) and milk production (Williams et al., 1991; Wohlt et al., 1991; Piva et al., 1993), whereas other studies (Erdman and Sharma, 1987; Arambel and Kent, 1990; Soder and Holden, 1999) found no response to yeast cultures. Similarly, in some studies, yeast cultures improved the digestibility of all nutrients (Reddy and Bhima, 2003; Kumar and Reddy, 2004; Kumar and Ramana, 2008), whereas in other studies, no change in total tract digestibility was observed by yeast feeding (Kamra et al., 2002; Mruthunjaya et al., 2003). There are many factors which influence the effect of yeast such as environment, nutritional status, mode of feeding, type of strain used etc. Therefore, the present experiment was conducted to study the efficiency of selected yeast culture (Saccharomyces cerevisiae CNCM I-1077 strain) as a probiotic in Graded Murrah buffaloes.

\section{Material and methods}

Twelve graded Murrah buffaloes with an average body weight of $465.4 \pm 20.92 \mathrm{~kg}$ were randomly divided into two groups (Control and treatment) of six animals each. All the animals were kept in well ventilated shed with cemented floor and were dewormed before the start of the experiment. Animals in both the groups received a basal diet comprising of roughages and concentrates separately to meet the maintenance and production requirements (ICAR, 1998). Concentrates were offered twice daily at the time of milking and chopped hybrid Napier (APBN-1) was offered ad libitum. The animals in treatment group received yeast culture (Saccharomyces cerevisiae CNCM I-1077 strain) @ 0.5 g/animal/day. The yeast culture was administered by top dressing over concentrate mixture every day. Clean drinking water was offered to all the animals ad libitum during the entire period of the experiment. After 120 days of feeding, a digestion trial was carried out with an adaptation period of 2 days and collection period of 6 days.

All the animals were weighed before the start and after the experiment for two consecutive days and the average values were recorded as the actual body weight. During the digestion trial, the amount of feed (chopped hybrid Napier and concentrate mixture) offered, residues left and faeces voided was recorded. 
Influence of diet supplementation with Saccharomyces cerevisiae in Graded Murrah buffaloes

Table-1: Chemical composition (\% DMB) of feedstuffs

\begin{tabular}{lcc}
\hline Nutrient & Hybrid Napier (APB N-1) & Concentrate Mixture \\
\hline Dry Matter & 24.24 & 91.23 \\
Organic Matter & 91.20 & 92.34 \\
Crude Protein & 8.50 & 19.63 \\
Ether Extract & 2.19 & 5.14 \\
Crude Fibre & 36.84 & 12.05 \\
Nitrogen Free Extract & 43.49 & 55.52 \\
Total Ash & 8.98 & 7.66 \\
Neutral Detergent Fibre & 75.13 & 33.52 \\
Acid Detergent Fibre & 47.80 & 17.80 \\
Acid Detergent Lignin & 7.40 & 4.81 \\
Cellulose & 37.93 & 12.99 \\
Hemi-cellulose & 27.33 & 15.72 \\
\hline
\end{tabular}

Daily representative samples of the feeds, residue and faeces were collected and pooled animal wise. The samples were analyzed for the proximate principles as per AOAC (1997) and cell wall constituents as per Van Soest et al., 1991. The data generated were subjected for the test of significance (Snedecor and Cochran, 1976).

\section{Results and discussion}

The chemical composition of feeds and fodders used in the present study is shown in table 1. The average DMI of buffaloes during the digestion trial was 114.31 and $119.24 \mathrm{~g} / \mathrm{kg} \mathrm{W0.75}$ equivalent to 2.49 and $2.57 \mathrm{~kg} / 100 \mathrm{~kg} \mathrm{BW}$, respectively, in control and treatment groups (Table 2). Although differences in dry matter intake between the two groups were nonsignificant but an improvement in intake was observed on yeast supplementation which may be partly due to improved rate of fibre breakdown (Martin and Nisbet, 1992) and partly by improved duodenal flow of absorbable amino nitrogen. Similar results were observed by Garg et al. (2000) who reported increased DMI in HF cows by feeding yeast culture in the diet. On the contrary, Phondba et al. (2009) reported decreased DMI in crossbred cows fed yeast culture in the diet. The digestibility coefficients of dry matter, organic matter, crude protein, ether extract, crude fibre and NFE (Table 2) showed non-significant differences between control and treatment groups, though the values were found to be comparatively higher in the yeast supplemented group. The improvement in digestibility could be due to increased fibre breakdown (Dawson et al., 1990). Phondba et al. (2009) and Garg et al. (2009) reported non-significant improvement in digestibility of nutrients in ruminants on feeding yeast culture whereas Reddy and Bhima (2003) and Kumar and Ramana (2008) observed significant improvement in digestibility of nutrients on feeding yeast culture. The digestibility coefficients of fibre fractions were higher $(\mathrm{P}>0.05)$ in buffaloes fed with yeast culture as compared to the control group confirming the earlier reports of Garg et al. (2009).

The DCP (\%) and TDN (\%) content were observed to be $8.03,53.06$ and 8.15, 54.06 in control and treatment groups, respectively. However, no significant difference was observed between the two groups. Similarly, Garg et al. (2009) and Phondba et al. (2009) reported non-significant increase in DCP (\%) and TDN (\%) fed yeast culture in the diet whereas Kumar and Reddy (2004) reported significant increase in DCP $(\%)$ and TDN (\%) content fed yeast culture in the diet. The DCP intake in terms of $\mathrm{g} / \mathrm{kg} \mathrm{W0.75}$ and $\mathrm{kg} / 100 \mathrm{~kg} \mathrm{BW}$ was found to be 9.16 and 0.20 and 9.73 and 0.21 in control and treatment groups, respectively, which were higher than the requirement $(6.76 \mathrm{~g} / \mathrm{kg}$ W0.75) suggested by ICAR (1998). The TDN in terms of $\mathrm{g} / \mathrm{kg} \mathrm{W0.75}$ and $\mathrm{kg} / 100 \mathrm{~kg} \mathrm{BW}$ was found to be 60.44 and 1.29 and 64.52 and 1.37 in control and treatment groups, respectively.

The probable reasons for the contradictory findings can be explained by the difference in the level of yeast culture used. Many researchers felt that unless the level is not adequate, probiotic will not have any beneficial effect on the host.

It is concluded that yeast culture did not show any significant positive effect on nutrient utilization in graded Murrah buffaloes.

\section{Acknowledgement}

The authors are thankful to the Director of Research, SVVU, Tirupati for granting permission to carryout the research work at Buffalo Research station, Venkataramannagudem, West Godavari (Dt.), A.P.

\section{References}

1. Arambel, M. J. and Kent, B. A. (1990): Effect of yeast culture on nutrient digestibility and milk yield response in early to mid lactation dairy cows. J. Dairy Sci. 73: 1560-1563.

2. AOAC (1997): Association of Official Analytical Chemists, 
Influence of diet supplementation with Saccharomyces cerevisiae in Graded Murrah buffaloes

Table-2: I nfluence of feeding yeast culture on nutrient intakes, digestibility and plane of nutrition of Buffaloes

\begin{tabular}{lcc}
\hline Parameter & Control Group & Treatment Group \\
\hline Dry Matter Intake & & \\
Kg / day & $11.24 \pm 0.27$ & $11.95 \pm 0.46$ \\
Kg / 100 kg BW & $2.49 \pm 0.13$ & $2.57 \pm 0.13$ \\
g / kg W0.75 & $114.31 \pm 4.14$ & $119.24 \pm 4.82$ \\
Digestibility (\%) & $54.94 \pm 1.71$ & $56.48 \pm 1.56$ \\
Dry Matter & $57.17 \pm 1.45$ & $58.61 \pm 1.49$ \\
Organic Matter & $60.71 \pm 1.11$ & $62.85 \pm 1.51$ \\
Crude Protein & $64.75 \pm 1.28$ & $66.72 \pm 0.79$ \\
Ether Extract & $50.57 \pm 1.69$ & $53.24 \pm 1.1$ \\
Crude Fibre & $60.12 \pm 1.4$ & $60.63 \pm 1.7$ \\
Nitrogen Free Extract & $51.71 \pm 1.69$ & $54.28 \pm 1.36$ \\
NDF & $48.24 \pm 2.29$ & $51.18 \pm 1.3$ \\
ADF & $52.4 \pm 2.23$ & $54.11 \pm 1.35$ \\
Cellulose & $57.11 \pm 1.33$ & $59.15 \pm 1.6$ \\
Hemi-Cellulose & & \\
Plane of nutrition & $8.03 \pm 0.18$ & $8.15 \pm 0.21$ \\
DCP (\%) & $53.06 \pm 1.27$ & $54.06 \pm 1.28$ \\
TDN (\%) & & \\
Intake of digestible nutrients (g / kg W0.75) & $9.16 \pm 0.31$ & $9.73 \pm 0.48$ \\
DCP intake & $60.44 \pm 1.51$ & $64.52 \pm 3.20$ \\
TDN intake & & \\
\hline
\end{tabular}

Official Methods of Analysis. 16th Edn. Maryland.

3. Dawson, K.A., Newman, K.E. and Boling J.A. (1990): Effects of microbial supplements containing yeast and lactobacilli on roughage fed ruminal microbial activities. $J$. Anim. Sci. 68: 3392 .

4. Erdman, R. A. and Sharma, B. K. (1989): Effect of yeast culture and sodium bicarbonate on milk yield and composition in dairy cows. J. Dairy Sci. 72: 1929-1932.

5. Garg, D.D., Sharma, T. and Dhuria, R.K. (2009): Evaluation of groundnut straw based complete feed blocks alone and in combination with yeast in ration of sheep. Anim. Nut. Feed Tech. 9(2): 137-144.

6. ICAR (1998): Nutrient requirements of livestock and Poultry. Indian Council of Agricultural Research, New Delhi, India.

7. Kamra, D. N., Chaudhary, L. C., Neeta Agarwal., Singh, R. and Pathak, N. N. (2002): Growth performance, nutrient utilization, rumen fermentation and enzyme activities in calves fed on Saccharomyces cerevisiae supplemented diets. Ind. J. Anim. Sci. 72(6): 472-475.

8. Kumar, M. K. and Reddy, G. V. K. (2004): Supplementation of yeast culture (Saccharomyces cerevisiae) to roughage based rations in crossbred heifers. Ind. J. Anim. Nut. 21(1): 36-39.

9. Kumar, M. K. and Ramana, D. B. V. (2008): Effect of supplementation of yeast culture to calves fed with complete diet. Ind. Vet. J. 85: 667-669.

10. Mruthunjaya, H. S., Kailas, M. M. and Thirumalesh, T. (2003): Effect of supplementation of live yeast culture on nutrient digestion and milk production in crossbred dairy cows. Ind. J. Anim. Nut. 20(1): 105-108.

11. Martin, S.A. and Nisbet, D.J. (1992): Effect of direct fed microbials on rumen microbial fermentation. J. Anim. Sci. 75: 1736-1744.

12. Phondba, B.T., et.al. (2009): Effect of feeding probiotic feed supplement on yield and composition of milk in crossbred cows. Anim. Nut. Feed Tech. 9(2): 245-252.

13. Piva, G., Belladona, S., Fusconi, G., Sicbaldi, F. (1993): Effect of yeast on dairy cow performance, ruminal fermentation, blood components and milk manufacturing properties. J. Dairy Sci. 76: 2717-2722.

14. Reddy, G. V. N. and Bhima, B. (2003): Effect of yeast culture based diet on growth and nutrient utilization in Deoni bul calves. Ind. J. Anim. Nut. 20(1): 101-104.

15. Snedecor, G. W. and Cochran, W. C. (1976): Statistical methods (7th edition), Oxford and IBH Publishing Company, Kolkata.

16. Soder, K. J. and Holden, L. A. (1999): Dry matter intake and milk yield and composition of cows fed yeast prepartum and postpartum. J. Dairy Sci. 82: 605-610.

17. Van Soest, P. J., Robertson, J. B. and Lewis, B. A. (1991): Methods of dietary fibre, neutral detergent fibre and nonstarch polysaccharides in relation to animal nutrition. $J$. Dairy Sci. 74: 3583-3597.

18. Williams, P. E. V., Tait, C. A. G., Innes, G. W. and Newbold, C. J. (1991): Effect of the inclusion of yeast culture (Saccharomyces cerevisiae plus growth medium) in the diet of dairy cows on milk yield and forage degradation and fermentation patterns in the rumen of steers. J. Anim. Sci.69: 3016-3026.

19. Wohlt, J. E., Finkelstein, A. D and Chung, C. H. (1991): Yeast culture to improve intake, nutrient digestibility, and performance by dairy cattle during early lactation. J. Dairy Sci. 74: 1395-1400. 